\title{
The Effect of Nurses and Midwives' Research Knowledge, Attitude and Skills on Patient Outcomes: A Literature Review and Conceptual Framework
}

\author{
Tumbwene E. Mwansisya, BSc(Hons), MSc, Ph.D. \\ Department of Public health, School of Nursing and Public health, University of Dodoma, Dodoma, \\ Tanzania
}

\begin{abstract}
Researchers have demonstrated that educational interventions can be effective at increasing the knowledge and skills associated with evidence-based practice including reproductive, maternal and child health care. However in developing countries like Tanzania, little attention has been paid for interventions that focus on capacity building for evidence-based practice among nurses and midwives in the clinical settings. A lack of research evidence-based practice in clinical setting contributes to as many as $30 \%-40 \%$ of patients not receiving care and some $20 \%-25 \%$ of patients may receive potentially harmful care. Thus, this article reviews the growing body of research on operational research training for nurses and midwives and its effectiveness to patient outcomes. This serves as the first step for capacity building on operational research to nurses and midwives in Tanzania.
\end{abstract}

\section{BACKGROUND}

Midwives and nurses in many countries in the world contribute more than $50 \%$ of all health care providers in the health care systems (Tanzania Nurses and Midwives Council, 2007). Though the use of research evidence in midwifery and nursing practices has been found to result in better outcomes for patients; often midwives and nurses fail to incorporate the current research findings into their practices (Esterbrooks et al., 2005). A lack of research evidence-based practice in clinical setting contributes to as many as $30 \%-40 \%$ of patients not receiving care and some $20 \%-25 \%$ of patients may receive potentially harmful care (Schuster et al., 1998).

The target for Millennium Development Goal 5 was to reduce the maternal mortality ratio (MMR) by three-quarters from 1990 to 2015 (United Nations, 2006). In developing countries like Tanzania, though statistics shows a significant decrease in maternal mortality ratio by 55\% from 1990 to 2013 with an annual percentage change rate of $-3.5 \%$, yet, the current MMR of 410/100,000 live births and perinatal mortality rate ranging from $42-125 / 1000$ births (WHO, 2014) is unacceptably high. The reason related to failure to reach the MDG number 5 remains unknown. Probably this failure might be resulting from little use of evidence based practice by the nurses and midwives who are the main health workforce. Therefore, this calls an urgent need for implementation of effective evidence-based care to reduce these burdens.

Researchers have demonstrated that educational interventions can be effective at increasing the knowledge and skills associated with evidence-based practice including reproductive, maternal and child health care (Sherriff et al. 2007). However in developing countries like Tanzania, little attention has been paid for interventions that focus on capacity building for evidence-based practice among nurses and midwives in the clinical settings. Thus, there is an urgent need to conduct interventional programs on operational research training for nurses and midwives and evaluating its effectiveness through measuring patient outcomes.

\section{RESEARCH-BASED KNOWLEDGE AND SKILLS}

It universally accepted that the aim of any research is to generate knowledge. Some researchers has argued that the failure to distinguish between clinical and theoretical researches to be a major cause of the theory-practice gap in midwifery and nursing professions (Rolfe, 1998; McCaughterty, 1991). The research that generates knowledge for the nursing clinical judgment is best taken by nurses 
themselves; because the knowledge is only relevant to the unique clinical situation of which a nurse is a part (Rolfe 1998). The Department of Health, England has addressed theory practice gap by stating that all clinical practice should be founded on up-to-date information and research findings (Department of Health (DOH), 1989). However, in developing countries it remains elusive to whether midwives and nurses do practice with up-to-date clinical-based research evidence.

\section{RESEARCH ATtitude}

Midwives and nurses attitudes towards research has been associated with the age of nurses, knowledge about research methods and the clinical settings in which they are employed (Kuuppelomäkia and Jouni, 2005; Berggren, 1996). However, others studies have suggested that clinical judgment or moral evaluation of patients to be socially embedded and depends on the pervasive norms and attitudes of particular midwifery and nursing units, independent of patient characteristics (McCarthy, 2003; McDonald et al., 2003). The midwives' attitude towards research is reinforced by their perception of organizational priorities. To achieve the millennium development goals, health care policy and midwifery and/or nursing professions need to change the attitude towards research so as to fill the research and clinical practice gaps and embrace a culture of evidence-based practice.

\section{The Relationship Between Research Skills, Midwives/Nurses Roles and Patients OUTCOMES}

As early as the Florence Nightingale era, research evidence-based practice has surfaced as a major concern in Midwifery and nursing professions (Upton, 1999; Montgomery, 2001). To date, research is considered as a core feature of the midwives and nurses' professional role and responsibility (McMillan and Conway, 2003). The research-based skills have been entangled with the efficiency, effectiveness and quality improvement in health care systems (Wallin et al., 2003). Moreover, the researchers have demonstrated that educational interventions can be effective at increasing the knowledge and skills associated with evidence-based practice that is associated with better patients' outcomes (Sherriff et al. 2007). The patient's satisfaction has emerged as a critical measure for patients' health care outcomes (Davies, 1999) because it has been associated with increased likelihood of adherence to medical recommendations (Sherbourne et al., 1992). Moreover, a systematic review of the research literature revealed individual determinants such as beliefs, attitudes, education, information-seeking and professional characteristics to be associated with research utilization (Esterbrooks et al., 2003). Therefore, the midwives and nurses' evidence-based practice can be measured through patient's satisfaction. The interventional research training which aims at improving evidence-based practice and adherence to medical and midwives/nurses recommendations by patients will help to achieve the Millennium development goal such as MDG goal number 5 in reducing newborn and maternal mortality.

\section{THE RATIONALE FOR LOCAL EVIDENCE-BASED RESEARCH}

The situation in developing countries is very different compared to the situations in developed countries, where most of the previous studies were conducted. There have been limited wellestablished clinical research skills for midwives and nurses in developing countries like Tanzania. Most of the conducted researches are related to requirement for graduation and all such researches are theoretical-based researches that aim at generating and testing theories and models that have been urged to the major cause of the theory-practice gap in midwifery and nursing profession. Thus, it is reasonable to initiate the training programs that focus on enabling midwives and nurses working in the reproductive, maternal, child health and other clinical as well as community settings, because provides care to the most vulnerable group in the population. Also, observing behavior in 'real world' settings has been suggested to provide accurate information about the transfer of new behaviors from training programs to other contexts.

\section{Conclusions}

The available evidence-based practice in nursing and midwifery practices in developing countries like Tanzania is based on developed countries research studies. However, socio-cultural determinants between the settings are different. Moreover, Most of these skills have been mainly provided through lecture-based courses. There has been no any focus on generating local research based knowledge, skills and practice. Therefore, the previous training programs have significant methodological 
The Effect of Nurses and Midwives' Research Knowledge, Attitude and Skills on Patient Outcomes: A Literature Review and Conceptual Framework

problems: 1) the lack of clinical research skills component. It is difficult for midwives who have very limited experiences in reproductive, maternal and child health to develop effective clinical skills and to utilize the related knowledge in everyday clinical work without research skills training. 2) Most of these training programs are not evaluated. However, It is important to evaluate clinical skills pre- and post-training to determine if a training program actually changes the behavior of midwives/nurses in the 'real world'. Thus, there is a need to implement and examine the effects of operation research knowledge, attitude and skills among midwives and nurses in developing countries like Tanzania.

\section{CONCEPTUAL FrameWORK}

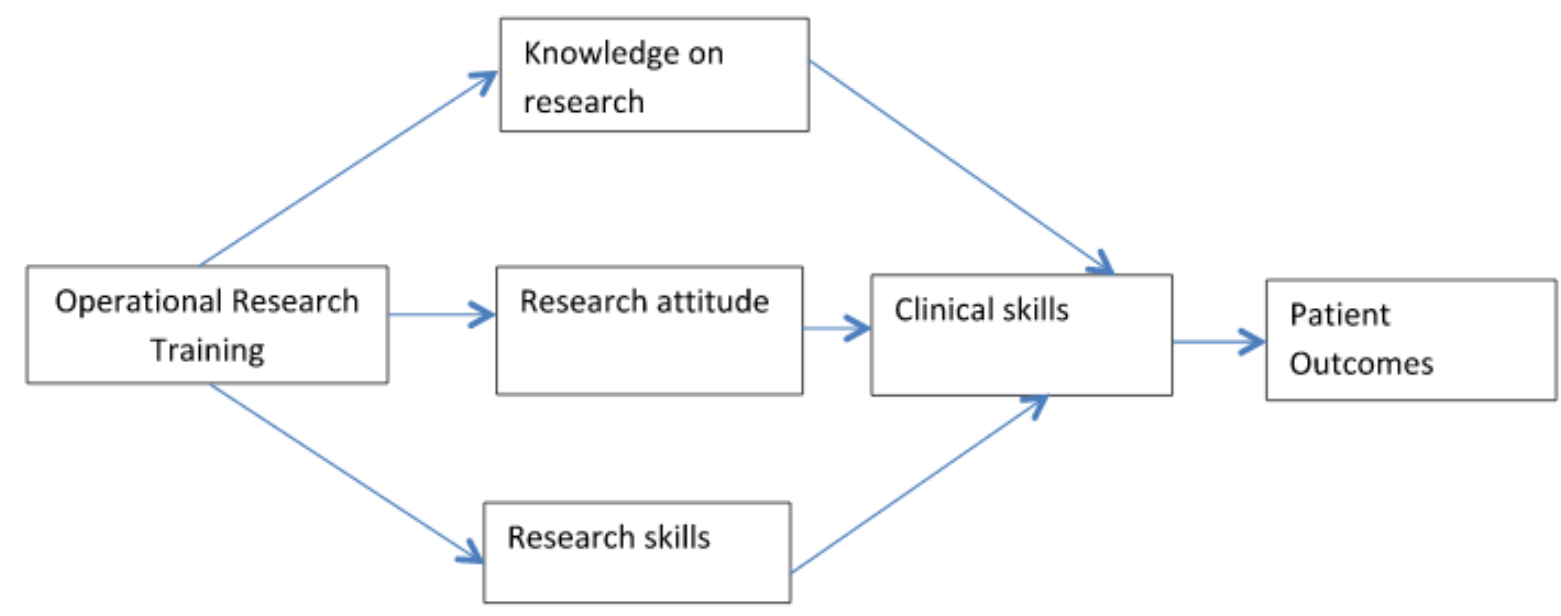

Figure1. Illustrates the Pathway of Impact of Operation Research on Patient Outcomes. Operational Research Training to Nurses And Midwives is Likely to Build Their Knowledge Attitudes and Skills on Research Capacity. When Barriers Towards Research Utilization have been Controlled the Nurses And Midwives are Likely to Utilize the Acquired Research Knowledge and Skills with Positive Attitude Towards Evidence-Based Nursing Practice. Certainly, the Evidence-Based Practice Improves the Patient Outcomes.

\section{REFERENCES}

Berggren AC. Swedish midwives'awareness of, attitudes to and use of selected research findings. Journal of Advanced Nursing 1996;23:462-70.

Berggren AC. Swedish midwives'awareness of, attitudes to and use of selected research findings. Journal of Advanced Nursing 1996;23:462-70.

Department of Health (1989). A strategy for Nursing : A report of the steering committee. Department of Health, London

Esterbrooks C.A., Floyd J.A., Scott-Findlay S., O`Leary K.A. \&Gushta M. (2003) Individualdeterminants of research utilization: A systematic review.Journal of Advanced Nursing 43,506-520.

Esterbrooks CA, Chong H, Brigidear K, Profetto-McGrath J: Profiling Canadian nurses' preferred knowledge sources for clinical

Kuuppelomäkia M, Jouni T. Finnish nurses' attitudes towards nursing research and related factors. International Journal of Nursing Studies. 2005;42(2):187-96.

McCaughterty D 1991. The theory-Practice gap in nurse education:its cause and [\possible solutions. Journal of Advanced Nursing 16:1055-1061

McCarthy, M.C. (2003). Detecting acute confusion in older adults: Comparing clinical reasoning of nurses working in acute, longterm and community health care environments. Research inNursing and Health, 26, 203-212.

McDonald, D.D., Frakes, M., Apostolidis, B., Armstrong, B., Goldblatt, S., \& Bernardo, D. (2003).Effect of a psychiatric diagnosis on nursing care for nonpsychiatric problems. Research inNursing and Health, 26, 225-232.

McMillan M, Conway J. Using Research and Education to Change Practice Australian journal of Advanced Nursing. 2003;20(3):5.

Montgomery KS, Eddy NL, Jackson E, Nelson E, Reed K, Stark TL, et al. Global research dissemination and utilization: recommendations for nurses and nurse educators. Nursing and Health Care Perspectives. 2001; 22 (3):124-9. 
practice. Can J Nurs Res 2005, 37:118-140.

Rolfe, G. (1988). The theory - practice gap in nursing: from research-based practice to practionerbased research. Journal of Advanced Nursing 28 (3), 672-679.

Schuster M, McGlynn E, Brook R: How good is the quality of health care in the United States.Milbank $Q$ 1998, 76:517-563.

Sherbourne, C.D., Hays, R.D., Ordway, L., DiMatteo, M.R., Kravoitz, R. (1992). Antecedent of adhrerence to medical recommendations: Results from the Medical Outcomes. Jounal of Beahvioral Medicine, 15, 44-468.

Sherriff K.L., Wallis M. \&Chaboyer W. (2007).Nurses' attitudes to and perceptions ofknowledge and skills regarding evidence-based practice.International Journal of NursingPractice. 13, 363-369.

Tanzania Nurses and Midwives Council: Standards to support learning and assessment in practice September, 2007.

Upton D. How can we achieve evidence-based practice if we have a theory-practice gap in nursing today? Journal ofAdvanced Nursing. 1999; 29:549-55.

World Health Organization, UNICEF, UNFPA, The World Bank \& the United Nations Population Division. (2014). Maternal mortality in 1990-2013: Tanzania. Geneva: WHO.

Department of Health (1993). A strategy for Nursing : Report of the taskforce on the strategy for research in nursing, midwifery and health visiting. Department of Health, London

Davies, P. (1999). What is evidence-based education? British Journal of Educational

Studies, 47, 2, pp. 108-121.

Wallin, L., Bostrom, A-M., Wikblad, K., \&Ewald, U. (2003) 'Sustainability in changing clinical practice'. Journal of Advanced Nursing, 41(5): 509-518.

United Nations. 2006. "The Millennium Development Goals Report: 2006." United Nations Development Programme, www.undp.org/publications/MDGReport2006.pdf (accessed 6 January 2016). 